\title{
Book Review: The Cult of Pythagoras
}

\author{
James A.D.W. Anderson \\ james.a.d.w.anderson@btinternet.com \\ 88 Lower Henley Road, Caversham, Reading, England, RG4 5LE
}

Submitted: 2 May 2020

Revised: 14 December 2020

\begin{abstract}
We review "The Cult of Pythagoras: Math and Myths" by Alberto A. Martínez, 2012. The book sets out a number of mathematical myths and dissolves them by a combination of checking historical sources and calculating results using the mathematics of the time. We pay particular attention to a chapter on division by zero. We record the earliest dates for particular solutions to the problem of division by zero and the ambition to have total mathematical systems.
\end{abstract}

\section{Review}

We review The Cult of Pythagoras: Math and Myths by Alberto A. Martínez, 2012 [1]. This book is a popular work in the history of mathematics. The theme of the book is to set out a mathematical myth and dissolve it by a combination of examining historical documents and performing calculations in a manner appropriate to the time. In this way Martínez gets at what historical mathematicians "really" meant and exposes current prejudices. The overarching theme of the book is to debunk the mythologising of Pythagorus of Samos. Throughout the book Martínez takes care to set out both the myth and the historical reality. He draws various lessons from this, among them that mathematics is an invention of human creative imagination and is prone to change.

In Chapter 6, From Nothing to Infinity, Martínez, considers the problem of division by zero. He notes that proposed solutions have arisen and been discarded, only to arise again. Here we record the earliest dates of various proposed solutions that Martínez mentions. It is important to note that Martínez is following his own narrative arc and is not undertaking a historical survey of all approaches to division by zero. Therefore the dates provided in our review might be revised in the light of further research.

We state the solutions in their modern form and record dates Before Common Era (BCE) and Common Era (CE). The interested reader should consult Martínez for the historical formulation of the solution and references to historical documents. 
- Division by zero is undefined, Aristotle. Aristotle lived from 384 to $322 \mathrm{BCE}$, so this notion dates to $322 \mathrm{BCE}$ or earlier.

- Zero divided by zero is zero, Brahmagupta, $628 \mathrm{CE}$.

- One divided by zero is infinity, ascribed by Martínez to Brahmagupta, $628 \mathrm{CE}$.

- A number divided by zero is unchanged, Mahavira. Mahavira lived from 1114 to $1185 \mathrm{CE}$, so this notion dates to $1185 \mathrm{CE}$ or earlier.

- A number divided by zero is infinity, Bhaskara. Bhaskara lived from 1114 to 1185 CE. Martínez gives the date circa 1150 to this notion.

- Search for a universal algebra that would provide an answer to any problem that could be formulated in its symbols, Girolamo Cardanao. Cardanao lived from 1501 to 1576. Martínez assigns a date of 1540s to this notion.

- One divided by infinity is zero, Leonhard Euler. Euler lived from 1707 to 1783. Martínez indicates that this notion may date to 1770 .

- Zero to the power zero is one, anonymous footnote in an English translation of Leonard Euler, 1810. The footnote does not appear in Euler's original, 1770.

- Zero divided by zero has infinitely many meanings, i.e. a fully undetermined meaning, Martin Ohlm, 1828.

- Eli Maor's geometrical arithmetic, 2003.

- Transreal arithmetic, James Anderson, 2007.

- Zero times infinity has multiple solutions, Martínez, 2012. Martínez proposes this solution in The Cult of Pythagoras: Math and Myths, page 86. It is closely related to Martin Ohlm, 1828.

Martínez summarises some approaches to division by zero in his Table 9. Comparison of a Few Approaches to Zero and Infinity. The penultimate line has a mistake. Martínez writes " $\infty \times \infty=$ NaN" in the column IEEE 754 binary arithmetic, but the correct answer is $\infty \times \infty=\infty$.

\section{Conclusion}

The book The Cult of Pythagoras: Math and Myths by Alberto A. Martínez, 2012 , is a popular work in the history of mathematics that seeks to dispel various myths about mathematics and to draw lessons from them. We pay particular attention to Chapter 6 which deals with division by zero. We record the earliest dates for particular solutions to the problem of division by zero. These dates might be revised following further historical research. Martínez notes that Girolamo Cardanao sought a universal, that is a total, algebra. As Cardano lived from 1501 to 1576, this notion dates to 1576 or earlier. Martínez ascribes the date 1540s to this notion.

\section{References}

[1] Alberto A. Martínez. The Cult of Pythagoras: Math and Myths. University of Pittsburgh Press, 2012. 